\title{
CONTRIBUTION TO THE EVALUATION OF THE COMPLIANCE FOR NEW PRODUCTS WITH ASPECT RELIABILITY AND MAINTENANCE
}

\author{
Dr Radoljub Tomić * \\ Alfa University, Faculty for Strategic and Operating Management, Belgrade, Serbia \\ Dr Predrag Petrović \\ Institute Kirilo Savić, Belgrade, Serbia
}

Marija Petrović

Institute Kirilo Savić, Belgrade, Serbia

Development and promotion of the principles of harmonization of new products, it is very important, especially in technical systems and their components, which are applied and exploited in a transport vehicle. Quality and reliability of these products have to be high to make the product, and thus the system, first of all was safe, yet competitive in the global market. On the other hand, one of the conditions for the promotion of local products is increasing product competitiveness, while meeting the technical regulations, product quality, reliability and maintenance. When it comes to the proper functioning of the brake system of railway vehicles is a significant benefit to system maintenance. Bearing in mind that the braking system must fulfill a series of conditions in terms of quality of legislation, safety and reliability in all operating and other conditions, this paper describes the dynamics of maintaining a technical system, with special emphasis on the share of costs in relation to the price of the brake system of railway equipment vehicles. It is a new domestic product of IHP "First five" Trstenik-(PPT), with special reference to the component relating to the sealing element, the most sensitive part of the device in the brake system of railway vehicles.

Key words: Maintenance, Braking, Availability, Reliable, Railway, Compliance, New product, Costs

\section{INTRODUCTION}

When it comes to existing products, but the concept of project solutions, the successful operation of the brake system is significantly affected by the maintenance system. The very concept of product design solution, must include all aspects relating to benefits for its maintenance. This attitude almost always have to be aware of the concept of establishing a complex new product configuration $[16,06]$.

Technical system has the design and manufacture to be adjusted given environmental conditions and system reliability is treated as its internal (inherent) property, which can improve the structural and technological measures.

Cancellations technical system represents each event after which the system is unable to perform the required functions. Readiness or availability of a technical system is the probability that the system will successfully take effect and achieve the projected size of the output in minimum re- quired time period and the circumstances surrounding. Reliability theory is the science which deals with the legality of the failures of technical systems and their functional units (system, subsystem, assembly, subassembly, element).

From a practical viewpoint term reliability of the easiest and most complete to be considered as a property of the technical system to operate without failures in certain conditions and time periods. Reliability analysis involves analyzing continuous technical failure of the system and its functional units, as well as all the factors, which in some way influence the occurrence of failures. [01]

System maintenance management system is very complex, which applies to the brake system of railway vehicles, and will in this paper only indicate maintenance subsystem elements related to the brakes. The theoretical aspects of this problem are considered in and widely considered in the very knowen books and monographies $[16,10,02,15,18]$. 
System reliability is the probability that the system by entering in areas tolerances, successfully serve as criteria in the territory of a given, and given the projected weather conditions. It is based on the comparison of the criteria set functions and actual working capacity of the system functions.

Brake systems must comply with numerous quality demands, law regulations about safety issues and high reliability in all sorts of work regimes; the logic of maintenance has been described with special review on the share of expenses to the price of brake systems.

The sealing system, as the most sensitive assembly of the brake devices and system /epecially for this paper, which is produced by Industry of hydraulics and pneumatics »Prva Petoletka«Trstenik (PPT), will be particularly considered. Analysis of this problem are based on the standards and the system of documentation and production programme of PPT [18,12,05].

\section{BASIC MAINTENANCE ASPECTS}

Main objective technical systems of the railway (MS), refers to the provision of uninterrupted functioning of the system as a whole, provided that its subsystems are functioning properly (PS), and elements (EL). In order to fulfill the logical requirements that determine the overall goal, it is necessary to provide an adequate supply of spare parts (RD), and supplies. The level and quality of spare parts and causes the cost to the user invests in procurement, storage and controlled storage reserves $[16,06]$.
Availability of the system is a measure of the state of the system in terms of efficiency of entry into effect of the realization of output values of the system-level deviations allowed areas set of criteria in a given function, given the time and conditions of use. Size components, availability, caused a number of influences, defines the different parameters of the function linking no cancellation work and maintainability of the system functions on the basis of: operational, planned and built-in readiness.

Operational availability is by definition the probability that the system successfully take effect and go in areas tolerances set of criteria function at a given time in the given environmental conditions, as determined by the ratio of total time in the system and the total duration (total time in service and cancellation ), as will be shown further on.

Planned availability is the time in which it is not required and the efficient operation of the system, which is a function of operating conditions and operational levels of the organization and maintenance of the system is dependent on the structural characteristics of the system.

Built-availability is determined by structural measures benefits and minimum time necessary maintenance procedures.

Availability of the system is determined for certain parts of the system as a whole, based on the ratio of total working time (tr), the sum of the total time in service (tu), and the time of failure (to). [08]

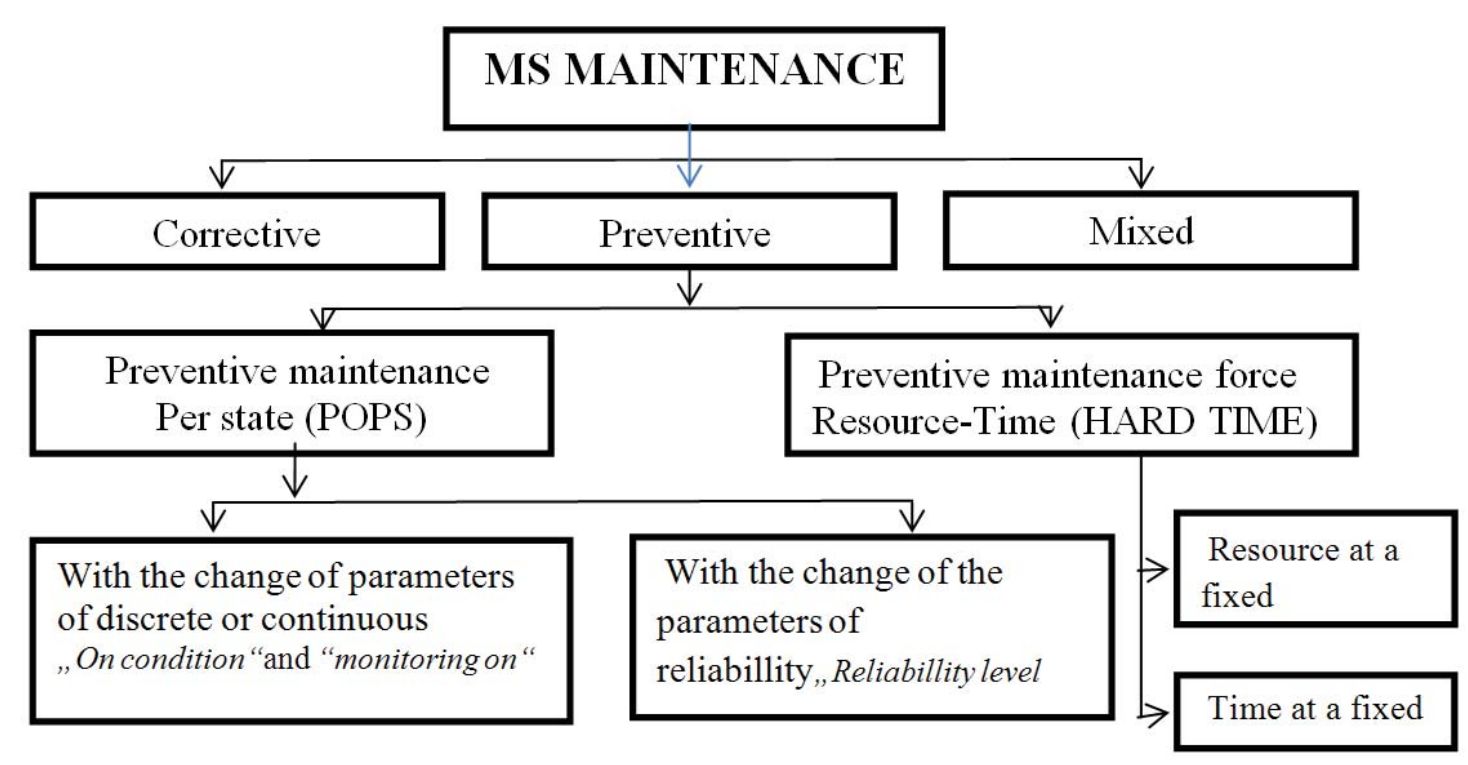

Figure 1: Concept of Maintenance Mechanical Systems (MS) 
Current standards ISO 9004 provides event fulfillment costs in managing the quality of products and mechanical systems, with most of the technical and production-control demands in terms of efficient operation of mechanical systems.

Proper maintenance is achieved by an efficient level of reliability and a high level of operational system. Possible concepts maintenance of mechanical systems are defined in Figure 1. [04]

Important to maintain the brakes on rail cars are the following:

- estimate, measure and record the frequency of the need for spare parts;

- determination of cases in which it is possible to apply the law of probability, as well as cases where you need permanent removal specific groups of causes;

- minimizing the costs of holding reserves, reserve reconstruction costs and expenses caused by not having a reservation.

Optimization of a new product in terms of technical and economic feasibility of this case is necessary for the railway company as a precondition of competitiveness in the market traffic with other transportation companies. To realize these goals requires research policies, standards, models and tools in the field of Reliability, Availability, Maintainability and Safety (RAMS) and Life Cycle Cost (LCC). Functionality models and tools and their continuous improvement in certain areas allow for effective incorporation into the design stages.

Standard EN 50126 defines the underlying processes in the field of railway RAMS is based on the life cycle of the system and the cost (LCCLife Cycle Cost), and the basic principles of management. When defining the parameters of rail systems in the area of RAMS and LCC's, the standard defines the correctness of the factors that may divide into three categories: sources of failure (system requirements), imposed factors during operation (operational requirements), undesirable, and the real phenomenon of a factor during maintenance (maintenance requirements). All these factors should be identified and assessed qualitatively, to the effect when operating in the life of the system was as efficient as possible.

Definition of the system over the RAMS and identify potential risks dangers that need to be analyzed and displayed for example. Frequency or through the matrix to the estimation of a sim- pler and more efficient at different levels (undesirable, intolerable, unbearable, negligible-(eg undesirable, intolerable, tolerable, negligible).

Standard EN 50126 defines the system life cycle as a series of stages that cover the overall lifetime systems and provide conditions for the planning, management, control and monitoring of all aspects of the system including the RAMS.

These stages are: Concept, system definition and application Conditions, Risk Analysis, System Requirements, Apportionment of system requirements, Design and implementation, Manufacturing, Installation, System Acceptance, Operation and Maintenance, Performance Monitoring.

Annex A gives a principal outline of RAMS specifications for rolling stock, identifying operating and environmental conditions, reliability targets, system failure modes and mean time between failures, maintenance and repair requirements (e.g. mean time to repair), safety targets, hazardous conditions, safety-related functions and failures, safety hazards severity levels, system availability.

Annex $B$ gives an outline procedure for a basic RAMS programme and lists some appropriate methods and tools for conducting and managing a RAMS programme. In particular, it refers to some procedures for performing deductive (top-down) and inductive (bottom-up) preliminary, worst case and in-depth RAMS analysis, which are included in separate standards. The most relevant procedures listed are: diagnostic testing, (FMEA-Failure Modes and Effect Analysis), (FTA-Fault Tree Analysis), (FMECAFailure Mode, Effects and Criticality Analysis), reliability block diagram method and Markov techniques.[18]

\section{SPECIAL ASPECTS OF BRAKE MAINTENANCE}

Only small parts of theoretical models, for understanding of the problem, will be discussed in this paper. Successful definition and realization of the brake design should prevent problems that may occur during its exploitation. It is clear that constructor should have in mind product features that will provide easy maintenance for the final user. Therefore, constructors have great responsibility to trace the reliability level (Rd), to define maintenance programme and to establish methodology for analysis of causes for improper functioning of brakes. Afterwards, based on observing concrete brake system, dur- 
ing some period of normal use, constructor has to perform revision of $(\mathrm{Rd})$ and to define control system for the real level of reliability (Rs), Fig. 2 , in adequate period of time (three month period, semiannual, annual), that depends of importance of the groups (PS) (subsystems) and

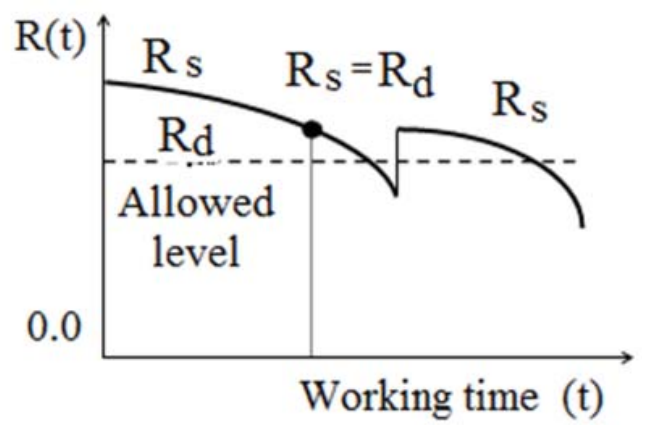

Figure 2: Model maintenance elements, method POPS-KNP

Maintaining of some elements using method (POPS-KNP - Preventive Maintenance by Condition with the Control Level of Reliability), can be applied in maintenance of (EL) which don't have essential importance in brake system, but have importance in aspect of economy (cost minimization), for finding out possibilities of selective application. Such an approach in the literature is generally referred to as POPS-KNP (Preventive Maintenance by Condition with the Control Level of Reliability).

Preventive maintenance is a series of actions necessary to prevent it fails, or the maintenance of the criterion function within the permissible deviations in the long term. It is performed on the basis of speculation fails it is studying the weather conditions of the previous period of the same or similar systems Which are based on time intervals prescribed maintenance procedures implementation. Depending on the characteristics of emergence and implementation of time are adjusted structure and running time of the procedure, Which Enables the adaptive system for preventive maintenance. This approach is typical of the new systems that do not have enough information from weather conditions or exploitation process. [08]

Costs of reserve possession are related, in the first place, on purchase costs of reserve, costs of storage, securing, keeping and maintaining. Costs of reserve renewal are related with the costs of ordering, communication, transport, checking and storage.
(EL) (elements) for the safety and quality work of brake system. If the value of (RS) is below (Rd), an analysis of causes has to be carried out, and some measures for increasing reliability have to be taken.[16, 05]

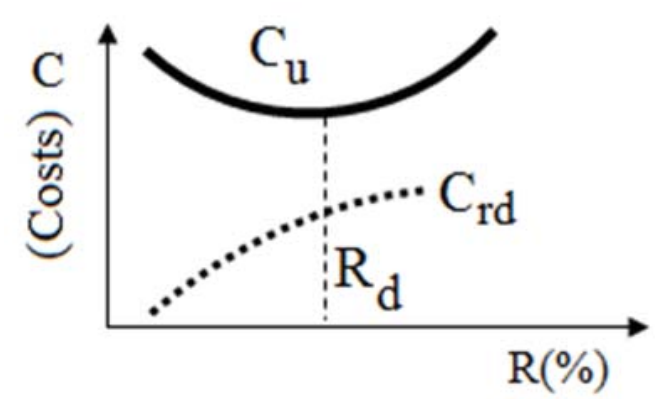

Figure 3: Relation of $\mathrm{Cu}$ and Crd costs, as a function of allowed reliability level $R d$

Costs of non-possessing reserves are related to interruption of device or brake system function, profit loss, risk of major damage and costs of emergency delivery, price increase etc.

Relation between spare parts costs ( $\mathrm{Crd}$ ) and total costs $(\mathrm{Cu})$, for allowed reliability level $(\mathrm{Rd})$ is presented on Figure 3.

Optimization of guaranteed reserve is for each part separately; expenses level particularly depends on:

- type of brakes,

- life cycle of devices and systems,

- quality system of handling and maintaining,

- presence of manufacturer of (RD=SP) (spare parts) on the market.

The aim is to accomplish appropriate or wanted reliability level with minimal total maintenance expenses. For the reason of limited size of this paper, only usual functioning scheme of specialized workshops for maintenance of vital brake devices will be presented, Figure 4.

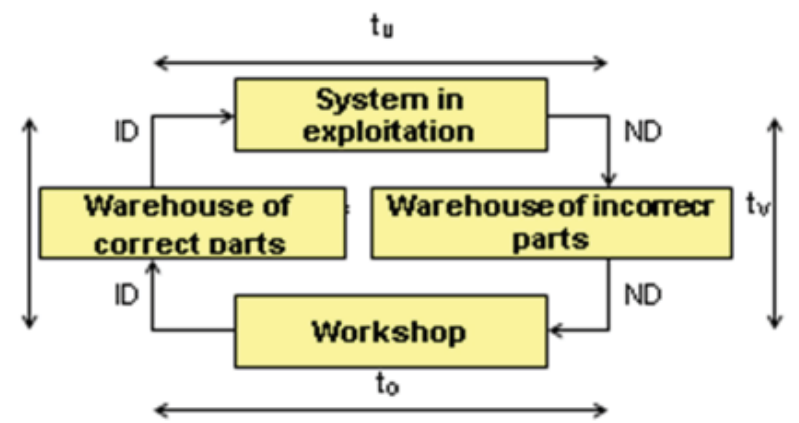

Figure 4: Functioning scheme of specialized work shops: tu-time of use, tv-idle time, to-repairing time, ts-free time, ID-correct part, ND-incorrect part 


\section{RESERVE OPTIMIZATION}

When a system successfully performs the function of set criteria, it is said that the system meets the and is in operation. Otherwise, when the system does not satisfy, or does not function successfully set of criteria, indicates that the system is in failure and determined that it violated the interdependence of the elements and the relationships between them and their features, and it is necessary to take measures to return the system to work. [08]

In practice, two of the most frequently used systems for the renewal of the reserves are [16, 02]:

- system of periodic renewal,

- $\quad$ system of renewal according to quantity level of reserve.

System of periodical renewal means renewal of reserve in equal time intervals and the renewed quantities are different. Purchased quantity depends of $(R d)$, i.e. of reserve achieved by it, Figure 5 .

This system is applied on the reserves spent in large scale and evenly. Time elapsed from ordering moment $(R D)$ to their delivery in warehouse

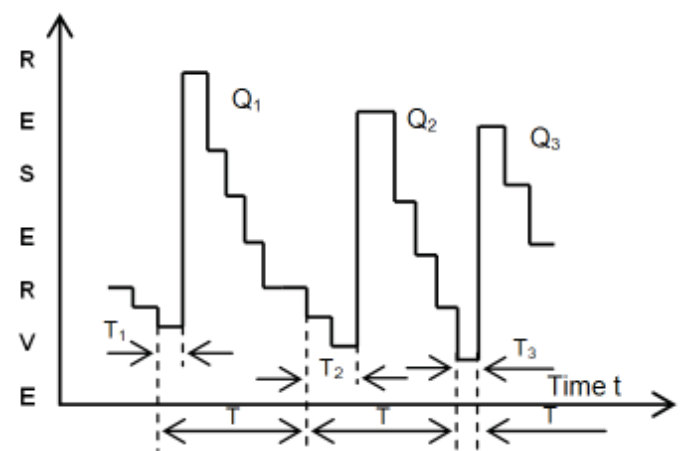

Figure 5: System of periodic renewal of the reserve

System of renewal according to quantity level of reserve is shown on the Fig.6. Application of both systems ensures control of costs and provides proper safety of brake system. Managing reserves can be observed as few random values, where rule of distribution is properly described by Poisson's distribution. In this case reliability can be easily calculated according to equation (1).

$P=\sum_{r=0}^{n} \frac{(\lambda t)^{r}}{r !} e^{-\lambda t}$

Where:

- P - reliability achieved with "r" complete sets of elements in reserve,

- $r$ - number of complete sets in reserve, is marked with $T_{p}=T_{1}+T_{2}+T_{3}$. Therefore, time of vulcanization and entry time of sealing material in warehouse should be considered (Table 1).

What defines a probability distribution law of distribution according to (Equation 1) is called a Poisson distribution, introduced by Simeon Denis Poisson (1781-1840) as a limiting case of binomial distribution provided a large number of experiments, and the probability $(p)$ of occurrence of event $(A)$ in each experiment small. [14]

Poisson distribution law defines the boundary layer binomial model, when the volume of samples of part mechanical system tends to infinity, provided that the product of the sample size and the probability of the observed events remain limited. So Poisson, the model used to describe the probability of rare mutually independent (requirement for binomial law) events such as failures of individual components of mechanical systems. Random variable is the realization of a rare event in a given time interval weight. Random variable $(r=0,1,2,3, \ldots . .$.$) , a Poisson$ distribution if in equation (1), value $(\lambda)$ a positive number.

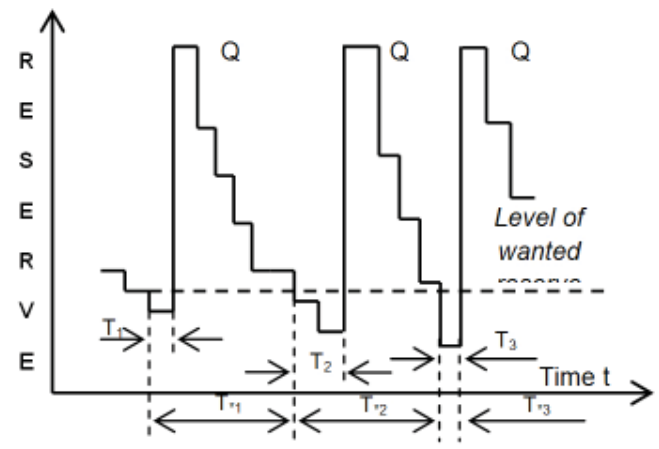

Figure 6: System of renewal according to the quantity level of wanted reserve

- $\lambda$ - frequency of reserve usage,

- $\mathrm{t}$ - time unit.

User should form nomograph based on experience and analysis, which ensures that determination of guaranteed reserves relies on factors as: ordering time and establishing (RD), costs of reserve elements and expenses of non-possessing reserve.

Experienced by the example of the same-type elements of the complex technical system with approximately constant intensity of failure, (POPS-KNP -Preventive Maintenance by Condition with the Control Level of Reliability) conception is recommended, also based on Poisson's distribution, equation (2) [16]: 
$P=\sum_{n=0}^{n_{g g r}} \frac{\left(\operatorname{\omega s} N a t_{s r}\right)^{n}}{n !} e^{-\left({\cos N a t_{s r}}\right)}$

Where:

$N$ - number of (sub)systems observed

a - number of the same-type elements in (sub)system

$t_{s r}$ - average time in element exploitation

$n$ - number of element failures during observed period of exploitation

$n_{g g r}-$ upper regulation limit

If $n<n_{g g r}$, then usage of (POPS-KNP) model is prolonged. Otherwise steps should be taken to increase reliability of elements by testing for causes of failure, revising project, change of exploitation conditions or change scale and frequency of control. If reliability could not be increased by these parameters, some other models of maintenance should be considered [16, 05].

\section{SEALING ELEMENTS APPLIED IN BRAKE SYSTEM DEVICES}

Sealing elements must be replaced in devices whether it is planned or not planned intervention on device.

Constructor has great responsibility to choose proper sealing system. Influence of high temperature, aggressive medium, light and ozone, are criteria for acceptability of construction solution. Also, hardness, tensile strength, extensibility, plastic deformation due to pressure, brittleness etc. are pointing to elastomers as adequate sealing material.

Elastomers used in brake system devices are based on NBR-caoutchouc, hardness from 45 to 80Sh. Determination of the temperature-time boundary is according to DIN 53546 (temperatures $100{ }^{\circ} \mathrm{C}$ to $160{ }^{\circ} \mathrm{C}$ and time from $4 \mathrm{~h}$ to $672 \mathrm{~h}$ ). Artificial aging of standard samples takes place in the stream of hot air according to DIN 53508 [18].

Selected physical properties observed during the testing are:

- breakdown dilatation,

- plastic deformation due to pressure,

- tensile strength.

Considering the request of the constructor that exploitation temperature varies from $-40{ }^{\circ} \mathrm{C}$ to $80^{\circ} \mathrm{C}$, used methods of selection and testing are guarantee for sealing system to work properly.

\section{EXPLOITATION LIFE TIME}

Under normal conditions for storage of sealing elements made of elastomers on NBR basis, maximal recommended intervals of time from their production to entry in warehouse, exit from warehouse to mounting, and their exploitation life time, are presented in the table 1.

If the time interval to reduce the installation, service life for so extended and vice versa.

Table 1: Number of three month period

\begin{tabular}{|c|c|c|c|c|}
\hline \multirow{2}{*}{$\begin{array}{l}\text { Element } \\
\text { type }\end{array}$} & \multicolumn{3}{|c|}{$\begin{array}{l}\text { Maximal period of time from the quarterly period that follows } \\
\text { quarterly period in which vulcanization has been accom- } \\
\text { plished }\end{array}$} & \multirow{2}{*}{$\begin{array}{l}\text { Exploitation life time, } \\
\text { counted from the } \\
\text { mounting }\end{array}$} \\
\hline & $\begin{array}{l}\text { Before entry in } \\
\text { warehouse }\end{array}$ & $\begin{array}{l}\text { Before exit from } \\
\text { warehouse }\end{array}$ & Before mounting & \\
\hline $\begin{array}{l}\text { O-ring, } \\
\text { Cuff, } \\
\text { Wiper } \\
\text { membrane }\end{array}$ & 4quartal/3months & 10quartal/3months & 16quartal/3 months & 20quartal/3 months \\
\hline
\end{tabular}

With more severe exploitation conditions exploitation life time must be shorter then shown in the table 1.

For example, when the parameter values from table 1, are assigned to equation (1) and requested reliability is defined at $\mathrm{Pd}>0.98$ (Pd $>98 \%)$, the results are below mentioned indexes for required complete sets of sealing elements, as guaranteed reserves for reliable exploitation of the brake system [08].
1) For $\lambda=0.200$ (reserve is used once in $t_{c r}=5$ year period) $\mathrm{P}_{(\mathrm{r}=0)}=0.819, \mathrm{P}_{(\mathrm{r}=1)}=0.983, \mathrm{P}_{(\mathrm{r}=2)}=0.998$

2) For $\lambda=0.111$ (reserve is used once in $\boldsymbol{t}_{c r}=9$ year period) $\mathrm{P}_{(\mathrm{r}=0)}^{c r}=0.895, \mathrm{P}_{(\mathrm{r}=1)}=0.994, \mathrm{P}_{(\mathrm{r}=2)}=0.999$

3) For $\lambda=0.087$ (reserve is used once in $t_{c r}=11.5$ year period) $P_{(r=0)}=0.917, P_{(r=1)}=0.996, P_{(r=2)}=0.999$ 
4) For $\lambda=0.080$ (reserve is used once in $t_{c r}=12.5$ year period)

$$
P_{(r=0)}=0.923, P_{(r=1)}=0.997, P_{(r=2)}=0.999
$$

Relation between $\mathrm{P}(\lambda, r, t)$ based on the above mentioned results is shown in the Figure 7.

Practically, with the reserve of one sealing elements complete set, $\mathrm{Pd}=98$ can be accomplished; in the case when mounting is performed immediately after the material left the warehouse, achieved reliability would be at level $\mathrm{P}>\mathrm{Pd}$, i.e. $\mathrm{P}=0.99$ ( $\mathrm{P}=99 \%)$.

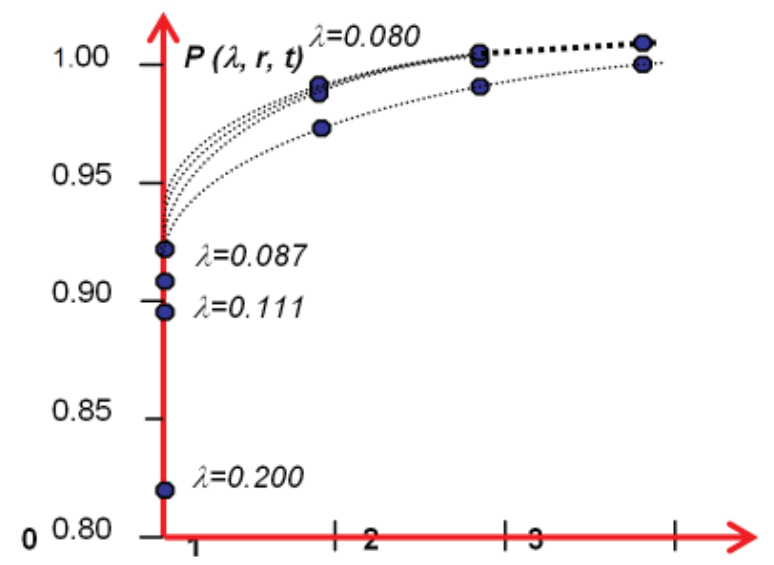

Figure 7: Relation between $P(\lambda, r, t)$

The conclusion is that it is possible to increase system reliability with minimal reserve only in wellequipped market with spare sealing elements, i.e. with high competition level of reliable producers, and other relevant preconditions for the existence of reliable extern reserves. We have been observing that case, so it is obvious that costs of reserve possessing can be minimized.

\section{SOME INTERNATIONAL EXPERIENCE IN RAILWAY VEHICLES BRAKE}

The braking system is a very important aspect of the security subsystem rolling stock. The process of applied technology on the brakes and other systems is very important to the rail service. In China, a group of authors conducted a reliability analysis method using FMEA and BCEU (Brake Control Execution Unit) and in doing so revealed some weaknesses in the components of the braking system to the application statistical analysis of stochastic processes significantly improve system reliability evaluation. [11]

In order to improve the reliability and scheduled maintenance brake system of railway vehicles, using the relevant techniques, from classic to new models introduced. Some methods and if they are present for several years, though in practice many are not available because of the extra costs and are increasingly using sophisticated control algorithms and the use of special sensors to detect errors in braking systems, and can be used on other mechanical systems. [07] As for the braking systems of railway vehicles, the introduction of the so-called interesting. vortex electric brakes, which are essentially based on eddy currents. It is a system ECB (Eddu Current Brake), which is mainly used for High-Speed Railway Train (HSRT). The system is suitable because it is independent of the point and the conditions of adhesion, whose coefficients may be variable, changing atmospheric conditions. Such a system reduces maintenance time, increases reliability, without additional electricity demands, as supplied from its own regenerative agregata. was donenumerous simulations regarding the design of the system and the control algorithm of the system uses a linear variation depending on the speed (ECB). Experimental studies have shown that achieving a constant torque on the wheel in the entire operating speed range, with a high degree of reliability. [03,09,01]

\section{CONCLUSION}

Theory base of maintenance of the technical systems and DIN 53000 series standard was used for analysis of a model for providing guaranteed reserve of sealing elements for the brake systems of the railway vehicles. [6]. For assigned reliability level $\mathrm{Pd}>0.98(\mathrm{Pd}>98 \%)$, with application of equation (1), the results have been gathered by identification of the guaranteed reserves of the sealing material and adequate reliability. Practically, with the reserve of one sealing elements complete set, in the case when mounting is performed immediately after the material left the warehouse, achieved reliability would be at level $\mathrm{P}>0.99$ ( $\mathrm{P}>99 \%)$.

The conclusion is that it is possible to increase system reliability with minimal reserve only in well-equipped market with spare sealing elements, i.e. with high competition level of reliable producers, and other relevant preconditions for the existence of reliable extern reserves. We have been observing that case, so it is obvious that costs of reserve possessing can be minimized. Considering application of sealing elements, in same category as in table 1 , we can conclude that if the period of time before mounting decreases, exploitation life time increases for the 
same value and opposite. With more severe exploitation conditions exploitation life time must be shorter then shown in the table 1 , so in that case intensity of failures would change, i.e. the number of reserves usage in unit of time would increase, which would affect to guaranteed reserve increase and appropriate expenses. Presented results confirm adequacy of theoretical base and accessibility of the shown concept for identification of model and quantification of indications relevant for referring guaranteed reserves of the brake system sealing elements for railway vehicles.

\section{Acknowledgment}

This work was created as a result of the project, the number of TR 35 031, entitled "Development and application of methods and laboratory equipment for conformity assessment of technical products," co-financed by the Ministry of Education and Science of Serbia, 2012.

\section{REFERENCES}

1) Basim Al-Naijar: „Just in time dynamic \& cost-efective maintenance (JIT DMAINT) for more reliable production: a case study", Journal of Applied Engineering Science (JAES), No. 2, 2012, Vol.10, ISSN 1451-4117, doi:10.5937/jaes 10-2132, UDC 33, p.107-115.

2) Čatić D., Tomić R., Pantić R.: „Steering of the light industrial vehicle", Third International Conference Heavy Machinery - HM '99, Kraljevo, 27-30. October, 1999., p.4.32-4.37.

3) Daley, S., Newton, D.A., Bennett, S.M., Patton, R.J.:" Methods for fault Diagnosis in Rail Vehicle Traction and Braking Systems", Mech. Eng. Centre, Eur. Gas Turbines Ltd., Leicester, Conference Publications, Qualitative and Quantitative Modelling Methods for Fault Diagnosis, IEE, 5/1-513, 1995.

4) Hong-Je Ryoo, Jong-Soo Kim, Do-Hyun Kang, Geun-Hie Rim,Yong-Ju Kim, ChungYuen Won: „Design and Analysis of an Eddy Current Brake for a High-Speed Railway Train with Constant Torque Control", Centre of Ind. Application, Korea Electrotechnol. Res. Inst., Changwon, Conference Publications, Industry Applications Conference, Conference Record of the 2000 IEEE, p. 277-281.

5) Internal documents, Industry of Hydraulics and Pneumatics »Prva petoletka«-Trstenik, (regulations, procedures, guidelines, software testing, reports, catalogs )
6) Jovančić M., Tomić R., Pantić R., „Basic aspects of maintaining the vacuum system for heat treating furnaces", 2 DQM Conference maintenance management”' '99”, Čačak, 1999., p.174-178.

7) Luo Min, Wu Meng-lin; Wang Xiao-yan: „Study On Reliability Test For Brake Control Execution Unit Of Rail Transit Vehicle“, Railway \&Urban Transit Inst., Tongji Univ., Shanghai, China, Conference Publications, p. 1-4, 2010.

8) Marković Z., Petrović P.:"Primena metode statističke kontrole procesa (SPC) sa aspekta kvaliteta proizvoda", Journal JUSK-a, No. 2, Vol.26, 1998.,p. 143-147.

9) Pacaiova H., Glatz J., Kacvinsky S., „Pozitive and negative aspect in application of maintenance management philosophy", Journal of Applied Engineering Science (JAES), No. 2, 2012, Vol.10, , ISSN 1451-4117, doi:10.5937/jaes 102132, UDC 33, p.99-105.

10) Popović P.: „Technical diagnostics and maintenance technology "- Analysis of reliability and maintainability engineering systems, University Singidunum, Excerpts lectures, 2010

11) S.Vukadinović: „Elementi teorije verovatnoće i matematičke statistike“, drugo izdanje,1978., Privredni pregled.

12) Series of standards ISO 9000 and DIN 53000.

13) Standard EN 50126.

14) Todorović J., Zelenović D.: „Efektivnost sistema u mašinstvu“, Naučna knjiga, Beograd, 1981.

15) Tomić R., Đurđević Ž.: „Key issues in the maintenance of hydraulic systems based on components and devices of the IHP program" ,"PPT” Hip-2000, Vrnjačka Banja, p.199-207.

16) Tomić R.,Bijelić S.,Tonić M.:“Basic principles on the quality of maintenance of mechanical systems in terms of optimal management of spare parts". (special topics, review), OMO, XXV, No. 2-3, Belgrade, 1996., p.101-108.

17) Tomić R., Jovančić M., Radovanović M., „Contribution to maintenance of brakes of the railway vehicle based on products made in IHP", "Prva petoletka", RaDMI 2002.,Vmjačka Banja, p.1443-1452.

18) Tomić R.:„Appendix objectification of domestic developments in relation to the quality system ISO 9000“, 5 DQM Conference "Dependability and Quality Management”, 2002., Belgrade, p.267-273.

Paper sent to revision: 13.03.2012.

Paper ready for publication: 05.12.2012. 